\title{
The Potential of Comprehensive Sex Education in China: Findings from Suburban Shanghai
}

\begin{abstract}
CONTEXT: More and more Chinese adolescents are engaging in premarital sexual activity. As a result, the numbers of unplanned pregnancies and sexually transmitted infections (STIS) among Chinese young adults have increased markedly.
\end{abstract}

METHODS: A comprehensive sex education program, including information on abstinence, contraception and healthy sexual behaviors, was carried out in a suburb of Shanghai. The program used six methods for providing information and services to unmarried 15-24-year-olds over a period of 20 months. Sexual behavior surveys were conducted among intervention participants and among controls in a comparable town, who did not receive a similar intervention; chisquare tests and logistic regression were used to compare the results.

RESULTS: Participation in the intervention was not associated with delayed sexual initiation, but was associated with reduced odds that youth coerced a partner into having sex (odds ratio, 0.3) and with increased odds of contraceptive use (6.2) and condom use (13.3) during the intervention period. The greater the level of participation, the larger the protective effects. Furthermore, the proportion of youth reporting pregnancy involvement during the intervention period was significantly lower in the intervention group than among controls (19\% vs. 26\%).

CONCLUSION: Comprehensive, community-based interventions may be effective in reaching large numbers of Chinese youth and in promoting sexual negotiation, contraceptive use, and pregnancy and STI/HIV prevention.

International Family Planning Perspectives, 2005, 31(2):63-72

A sexual revolution of sorts is under way in China, ${ }^{1}$ particularly among youth. Whereas a generation ago, prevailing attitudes toward sex were conservative by any standard and premarital sex was almost unheard of, today young people in China are increasingly open to more liberal ideas about dating and relationships. According to the 2000 Chinese Health and Family Life Survey (CHFLS), the first nationally representative survey on sexual behaviors and attitudes, four in 10 men younger than 30 say they have had premarital sex, more than twice the proportion among those in their 40s. The same trend appears among women. Two in 10 women younger than 30 report having had sex before marriage, compared with one in 10 of those in their $40 \mathrm{~s}^{2}$

Further studies show that growing numbers of high school and college students in China are engaging in sexual behavior. For example, an investigation conducted in 1989 showed that $13 \%$ of male and $6 \%$ of female college students had had premarital sex; in 1999, by contrast, 24\% of male and $12 \%$ of female seniors in a Guangzhou high school reported having had premarital sex. ${ }^{3}$ The proliferation of more liberal attitudes toward sexual behavior among Chinese young people has been traced back to the early 1980s, when economic reforms commenced, ${ }^{4}$ and is often attributed to the breakdown of traditional norms resulting from greater mobility, urbanization and the influence of mass media and Western culture. ${ }^{5}$

Increased sexual activity brings economic, social and, es- pecially, health concerns. More and more Chinese youth are grappling with issues related to contraception and pregnancy, sexually transmitted infections (STIs) and HIV, and sexual coercion. According to the 2001 Almanac of China's Health, as many as 10 million induced abortions are performed annually in China, and about 20-30\% are provided to unmarried young women. ${ }^{6}$ In a study of young women in Shanghai who were engaged to be married, $27 \%$ had aborted a pregnancy. ${ }^{7}$ Indeed, teenage pregnancy and premarital abortion have become a main public health issue in China.

China has witnessed an upsurge of STIs in recent years. ${ }^{8}$ Surveillance data indicate that between 1990 and 1998, the incidence of syphilis increased from 0.2 to 4.3 cases per 100,000 inhabitants, and the incidence of gonorrhea from nine to 24 cases per $100,000 .^{9}$ The CHFLS, which included a urine test for chlamydia, found high prevalence in cities and among people younger than $45 .{ }^{10}$ Furthermore, China is in the early stages of a major HIV/AIDS epidemic. ${ }^{11}$

In addition, concern about the prevalence of sexual coercion in China is increasing. Chinese women reportedly often submit involuntarily to the sexual desires of their husband or other primary sexual partner. ${ }^{12}$ And some evidence suggests that many Chinese adolescents who seek abortions have experienced sexual coercion. ${ }^{13}$ Thus, interest is mounting in implementing education and intervention programs that can successfully aid young people in making decisions and taking preventive measures that address these problems.
ByBo Wang,

Sara Hertog,

Ann Meier,

Chaohua Lou

and Ersheng Gao

Bo Wang is postdoctoral fellow, and Sara Hertog is a doctoral candidate, Department of Sociology and Center for Demography and Ecology, University of Wisconsin, Madison, WI, USA. Ann Meier is assistant professor, Department of Sociology and Minnesota Population Center, University of Minnesota, Minneapolis, MN, USA. Chaohua Lou is professor, and Ersheng Gao is professor, Shanghai Institute of Planned Parenthood Research, Shanghai, China. 
Sex education programs for young people have long been implemented in developed countries. In most Western countries, a variety of strategies and methods have been used to prevent STIs and unwanted pregnancies; their impact on adolescent sexual behavior remains controversial. ${ }^{14}$ A comprehensive review summarizing the results of 52 HIV/AIDS and sex education studies, most of which were conducted in the United States and Europe, ${ }^{15}$ revealed that nearly half of the programs resulted in no changes in onset of sexual activity, number of sexual partners, or unplanned pregnancy or STI rates; only 17 affected at least one of these outcomes. Likewise, pregnancy prevention initiatives do not appear to reduce rates of sexual activity among adolescents, ${ }^{16}$ although sex education programs have had some success in increasing rates of contraceptive use and reducing pregnancy rates. ${ }^{17}$ A rigorous evaluation of five adolescent pregnancy prevention programs conducted in the United States found decreased rates of sexual initiation resulting from four of the initiatives, increased rates of contraceptive use from three and decreased rates of pregnancy from two. ${ }^{18}$

Inconsistency in results of evaluations of sex education programs is not surprising, given the heterogeneity of researched initiatives. Sex education programs encompass curricula that vary widely in their aims, scope, implementation and content. ${ }^{19}$ Programs with vastly different goals, structures, lengths, delivery agents and theoretical underpinnings are often classified under the broad heading of sex education. ${ }^{20}$ As such, abstinence-oriented programs, HIV prevention initiatives, contraceptive education and programs limited to physiological topics tend to be grouped together, and this disparate grouping makes evaluations difficult. Another obstacle to evaluating the success of sex education programs in influencing behaviors arises from the use of self-reported, retrospective data, which often do not accurately reflect behavior. Inconsistent results among existing studies suggest that work remains to be done to determine which components of sex education are most effective in promoting healthy sexual behavior.

In China, schools and communities have responded to increased sexual behavior and its associated risks by implementing various sex education programs for adolescents. The majority of the efforts are aimed at increasing adolescents' knowledge of anatomical and physiological facts of human reproduction. ${ }^{21}$ Because teachers, policymakers and education administrators are concerned about the potential for inadvertently condoning or encouraging adolescent sexual behavior, topics related to contraceptive methods and alternatives are often excluded. Previous studies have shown that programs that cover these topics succeed in increasing sexual knowledge and, occasionally, in influencing young people's attitudes toward sex. ${ }^{22}$ Nevertheless, we are aware of only one study that speaks to the efficacy of sex education programs in influencing sexual behavior patterns in China. ${ }^{23}$

In this article, we report results from a community-based comprehensive sex education program targeting unmarried youth aged 15-24 in suburban Shanghai. Although various sex education programs have become common in China's high schools, and family planning services have long been available to married adults, this program was unusual in that it was designed both to delay sexual activity and to provide contraceptive knowledge and supplies to unmarried Chinese youth. We test the hypotheses that after participating in the intervention, adolescents were less likely to initiate sexual activity, more consistent in using contraceptives, less likely to be involved in sexual coercion and less likely to be involved in a pregnancy than were those who had not taken part in the program.

\section{METHODS \\ Survey Sites}

The study was carried out from May 2000 to January 2002 in two comparable towns in the suburban Songjiang district of Shanghai. Our choice of a suburban over an urban site for this project was based on two criteria. First, a large proportion of unmarried youth in Shanghai's suburbs are sexually active, and they have higher rates of premarital pregnancy and induced abortion than their peers in Shanghai's urban districts; these characteristics are associated with a widespread custom of cohabitation among engaged young people in suburban areas of Shanghai. ${ }^{24}$ Thus, we anticipated that prevailing attitudes and behaviors in the Songjiang district were well suited to testing an intervention. Second, Songjiang has a well-established district family planning commission. Thus, we had reason to believe that the intervention activities would receive some level of support from local health care workers.

Following selection of the research district, investigators interviewed local community leaders and service providers to identify possible intervention locations. The criteria for selection of the intervention town were that a high proportion of resident adolescents be sexually active, the population include at least 1,000 eligible adolescents, and the town have a good family planning network and qualified health providers to administer the program. The control town was chosen on the basis of its similarity to the intervention town on these three measures. In addition, we required that the two towns be far enough apart to minimize cross-contamination.

In May 2000, unmarried youth aged 15-24 in the two towns who were not planning to marry in the coming year and were willing to participate were enrolled in the study and completed a baseline survey. Initially, we invited 1,275 eligible youth in the intervention town and 1,087 in the control town to participate. Some youth refused for various reasons (e.g., they were taking college entrance examinations soon or were busy). In the end, 2,227 youth enrolled-1,220 in the intervention group and 1,007 in the control group, or $96 \%$ and $93 \%$, respectively, of those invited. Attrition prior to the end of the 20-month period amounted to $6 \%$ in the intervention group and $11 \%$ in the control group; thus, 1,148 and 894, respectively, completed the postintervention questionnaire in January 2002. Analyses are based only on those who participated in both interviews. 


\section{Intervention Components}

The intervention used six types of activities to provide information and services regarding abstinence, sexuality, contraception and HIV/AIDS prevention: distribution of educational reading materials, screening of educational videos, lectures, peer group discussions, and provision of reproductive health services and counseling. Most of the intervention activities (screening of videos, lectures, group discussions and provision of reproductive health services) took place on weekends, when most young people had time to participate. We describe the program as comprehensive sex education because it includes information on abstinence, contraception and healthy sexual behaviors. Although the intervention components were the same for high school students and out-of-school youth, abstinence was emphasized among high school students, because most of them were not sexually active at baseline, while safer-sex practices and contraceptive use were stressed among out-ofschool youth. Before the intervention was implemented, a health counseling center for youth was established at the family planning clinic in the intervention town. A full-time, credentialed female counselor was hired during the program period; she worked with project staff and 12 family planning workers to distribute educational materials and organize activities.

Nine brochures and pamphlets and four books were distributed to each participant in the intervention group during the 20-month study period. These materials addressed a wide range of issues: the growth and development of the human body, reproductive physiology, the development of healthy sexual attitudes and values (abstinence or, for sexually active youth, contraceptive use), dating and relationships, norms regarding the acceptability of sex and decision-making, sexual negotiation, consequences of premarital sex, the use and availability of contraceptives, avoiding unwanted pregnancy and preventing STIs

Three sex education videos, each lasting about 40 minutes, were shown in the intervention town's cinema. To improve attendance, the program showed a recreational movie after each educational film. The first film provided information on sexual development, sexual anatomy, masturbation and ejaculation, menstruation and feminine health, and nutrition and exercise. The second addressed body changes during puberty, development of sex organs, first ejaculation and menstruation, inborn penis diseases and orchitis, psychological characteristics during puberty, abstinence, and behavior norms and sexual ethics. The third focused on STI/HIV epidemics and prevention. The three films were attended by 873,583 and 562 viewers, respectively.

A qualified expert was asked to lecture on premarital sexual abstinence and pregnancy prevention in the intervention town's meeting room. The single session stressed premarital sexual abstinence as the most effective method for preventing pregnancy and infection. The speaker told several stories about unmarried youth seeking induced abortion, and counseled participants not to engage in early sexual activity because of its serious consequences. The speaker also encouraged young people to set life goals and to postpone sexual activity in favor of the pursuit of higher aspirations. In addition, the speaker introduced the use of condoms and emergency contraceptive pills, and suggested that sexually active unmarried youth stop their sexual activity or adopt safer-sex practices.

Youth in the intervention group received additional information on the risks associated with unprotected intercourse, methods for avoiding unwanted pregnancy, and personal responsibility for one's sexual behavior through facilitated peer group discussions. Discussions covered attitudes toward sexual behavior, consistent and correct condom use, use of emergency contraception, negative health consequences of premarital pregnancy and skills involved in sexual negotiation and decision-making. Additionally, participants shared their beliefs regarding effective methods for preventing unwanted pregnancy and STIs. In all, 36 group discussions were conducted during the intervention period. The discussions were organized by local family planning workers and took place at 10 village family planning clinics and the youth health counseling center.

To address individual youths' questions regarding sexuality and contraceptive use, a qualified counselor was made available for routine in-house and telephone counseling. During the intervention period, participants utilized the counseling services a total of 328 times. Most questions related to contraception, STIs, pregnancy, masturbation, sex refusal skills and life goals.

Finally, the program emphasized improving access to contraceptive services for sexually active participants. Contraceptive supplies were made available (with parental consent for minors) to the intervention group at no cost. Two strategies were used to expand contraceptive access: The program counselor provided various methods at the youth health counseling center during weekdays, and the health care personnel who led the peer group discussions scheduled clinic appointments for sexually active youth in need of reproductive health care or contraceptive services. In total, 4,348 condoms, 137 doses of oral contraceptive pills, 107 doses of spermicidal creams, 870 suppositories, 146 diaphragms, 106 doses of emergency contraceptive pills and 93 home pregnancy tests were distributed to participants.

Intervention elements were phased in after the 2000 survey, and the full-scale intervention was in place throughout 2001. On average, the 1,220 participants in the intervention group reported receiving 8.7 brochures or books (standard deviation, 2.2). Seventy-nine percent of participants viewed educational videos (average, 1.7 videos per participant; standard deviation, 0.6), 25\% attended group discussions (average, 1.4; standard deviation, 0.6 ) and $21 \%$ attended the only lecture. Only $11 \%$ of participants utilized the counseling services; the average number of counseling sessions per participant was 2.6 (standard deviation, 1.7). Each sexually active participant in the intervention group received an estimated 12 free condoms, on average, during the program period (assuming that only sexually active participants took condoms). 


\section{Survey Design}

Participants completed self-administered written surveys prior to and immediately following the 20-month intervention period. The surveys were anonymous and conducted in a private environment (community meeting rooms). Trained researchers provided explanations and instructions for completing the surveys, and were available to assist participants with any problems they experienced in understanding the questionnaire. Investigators reviewed all questionnaires for completeness and consistency. Responses to open-ended questions were grouped according to the frequency with which they occurred and then coded for analysis according to assigned categories.

The questionnaires collected information on participants' sex, age, education, family economic status (categorized as poor, average or rich), family structure, parents' discipline (strict, general or relaxed), dating status, feelings about family members (very good, good, less than good) and attitudes toward premarital sexual activity (disapprove, neutral, approve). Sexually experienced participants were asked numerous questions about their first and most recent intercourse, contraceptive use, experience of sexual coercion, pregnancy and induced abortion. The preintervention and postintervention questionnaires were similar in design and information collected.

\section{Analysis}

Both the baseline and the follow-up questionnaire contained measures of the major behavioral variables necessary to assess associations between program participation and youths' sexual behavior. Our primary variables of interest are participants' coital status and contraceptive use at baseline and at follow-up; experience of sexual coercion, condom use and pregnancy involvement during the program period; and whether the respondent was a member of the intervention or control group.

Sexual initiation is indicated by a dichotomous variable indicating whether the participant initiated sex during the 20-month period (coded 1) or did not (0). Similarly, sexual coercion reflects whether the participant forced a partner into sex (1) or not (0). Contraceptive use includes how consistently sexually active participants practiced contraception both before and after participation in the program, and what method or methods they used. Consistency of use is indicated by a multinomial variable-use every time (3), use frequently (2), seldom use (1) and never use (0). In addition, we analyzed whether participants had ever used a condom during the program period (1) or not (0). Pregnancy indicators assessed whether a participant had conceived or had impregnated a partner ( 1 for yes, 0 for no). Participation in the intervention group ( 1 ) is contrasted with participation in the control group (0).

In addition, we created a "treatment score," which indicates the degree to which individual program participants

*Weights were assigned to each intervention element, and the treatmen score was calculated as $0.3^{*}$ brochure $+1^{*}$ discussion $+0.5^{*}$ video $+0.5^{*}$ lecture $+0.5^{*}$ consultation.

\begin{tabular}{|c|c|c|}
\hline Characteristic & $\begin{array}{l}\text { Intervention } \\
(\mathrm{N}=1,148)\end{array}$ & $\begin{array}{l}\text { Control } \\
(\mathrm{N}=894)\end{array}$ \\
\hline \multicolumn{3}{|l|}{ ALL } \\
\hline $15-16$ & 13.2 & 13.9 \\
\hline $17-18$ & 41.2 & 42.6 \\
\hline 19-20 & 32.9 & 27.1 \\
\hline $21-22$ & 12.3 & 14.1 \\
\hline $23-24$ & 0.4 & 2.2 \\
\hline \multicolumn{3}{|l|}{ Sex } \\
\hline Male & 59.1 & 55.5 \\
\hline Female & 40.9 & 44.5 \\
\hline \multicolumn{3}{|l|}{ School status } \\
\hline Out of schoolt & 56.7 & 57.9 \\
\hline In school & 43.3 & 42.1 \\
\hline \multicolumn{3}{|l|}{ Family structure } \\
\hline Both parents & 96.3 & 95.4 \\
\hline Single parent & 3.7 & 4.6 \\
\hline \multicolumn{3}{|l|}{ Feeling toward family** } \\
\hline Very good & 37.5 & 30.1 \\
\hline Good & 41.1 & 44.5 \\
\hline$<$ good & 21.3 & 25.4 \\
\hline \multicolumn{3}{|l|}{ Family economic status** } \\
\hline Rich & 7.1 & 4.1 \\
\hline Average & 84.3 & 83.9 \\
\hline Poor & 8.5 & 12.0 \\
\hline \multicolumn{3}{|l|}{ Parents' discipline } \\
\hline Strict & 37.5 & 38.2 \\
\hline General/relaxed & 62.5 & 61.8 \\
\hline \multicolumn{3}{|l|}{ Dating } \\
\hline Yes & 22.3 & 19.4 \\
\hline No & 77.7 & 80.6 \\
\hline \multicolumn{3}{|c|}{ Attitude toward premarital sex } \\
\hline Disapprove & 11.3 & 12.4 \\
\hline Neutral & 34.4 & 30.7 \\
\hline Approve & 54.3 & 56.9 \\
\hline IN-SCHOOL YOUTH & $(\mathrm{N}=497)$ & $(\mathrm{N}=376)$ \\
\hline \multicolumn{3}{|l|}{ Type of school } \\
\hline Competitive public & 12.3 & 14.1 \\
\hline General public & 42.9 & 45.2 \\
\hline Vocational & 44.9 & 40.7 \\
\hline \multicolumn{3}{|l|}{ Level in school** } \\
\hline Junior high & 6.0 & 16.5 \\
\hline Senior high & 94.0 & 83.5 \\
\hline OUT-OF-SCHOOL YOUTH & $(\mathrm{N}=651)$ & $(\mathrm{N}=518)$ \\
\hline \multicolumn{3}{|l|}{ Education* } \\
\hline sjunior high & 39.0 & 50.4 \\
\hline Senior high & 53.0 & 45.6 \\
\hline$\geq$ college & 8.0 & 4.1 \\
\hline \multicolumn{3}{|l|}{ Occupation* } \\
\hline Factory worker & 60.6 & 66.2 \\
\hline Seeking employment & 25.4 & 25.2 \\
\hline Restaurant worker & 6.5 & 3.1 \\
\hline Teacher/technician/clerk & 7.5 & 5.6 \\
\hline Total & 100.0 & 100.0 \\
\hline
\end{tabular}

were exposed to intervention materials or services. * Peer group discussion was assigned the greatest weight because free contraceptives were distributed at the discussions. Because the brochures contain less information than the edu- 
TABLE 2. Percentage of participants reporting selected sexual behaviors, and percentage distribution of sexually experienced youth by frequency of contraceptive use, according to timing of survey and group assignment

\begin{tabular}{|c|c|c|c|c|}
\hline \multirow[t]{2}{*}{ Measure } & \multicolumn{2}{|l|}{ Baseline } & \multicolumn{2}{|c|}{ Postintervention } \\
\hline & $\begin{array}{l}\text { Inter- } \\
\text { vention }\end{array}$ & Control & $\begin{array}{l}\text { Inter- } \\
\text { vention }\end{array}$ & Control \\
\hline \multicolumn{5}{|l|}{ SEXUAL BEHAVIOR } \\
\hline All & $(\mathrm{N}=1,148)$ & $(\mathrm{N}=894)$ & $(\mathrm{N}=1,148)$ & $(\mathrm{N}=894)$ \\
\hline Hugging & 29.4 & 30.2 & 55.0 & 58.5 \\
\hline Kissing & 21.9 & 23.3 & 46.3 & 49.9 \\
\hline Intercourse & 9.7 & 11.0 & 30.8 & 33.1 \\
\hline In-school youth & $(\mathrm{N}=497)$ & $(\mathrm{N}=376)$ & $(\mathrm{N}=497)$ & $(\mathrm{N}=376)$ \\
\hline Hugging & 12.7 & 13.0 & 34.2 & 38.6 \\
\hline Kissing & 7.4 & 8.0 & 23.3 & 28.5 \\
\hline Intercourse & 0.8 & 1.1 & 8.1 & 9.3 \\
\hline \multicolumn{4}{|l|}{ Out-of-school } & $(\mathrm{N}=518)$ \\
\hline Hugging & 42.2 & 42.7 & 70.8 & 73.0 \\
\hline Kissing & 32.9 & 34.4 & 63.8 & 65.4 \\
\hline Intercourse & 16.4 & 18.2 & 48.2 & 50.4 \\
\hline \multicolumn{5}{|c|}{$\begin{array}{l}\text { CONTRACEPTIVE USE } \\
\text { Sexually experienced }\end{array}$} \\
\hline youth & $(\mathrm{N}=111)$ & $(\mathrm{N}=98)$ & $(\mathrm{N}=354)$ & $(\mathrm{N}=296)$ \\
\hline Used every time & 21.8 & 21.4 & 37.6 & $16.2^{* * *}$ \\
\hline Used frequently & 12.7 & 19.4 & 51.4 & 28.4 \\
\hline Used occasionally & 30.9 & 32.7 & 9.9 & 38.2 \\
\hline Never used & 34.6 & 26.5 & 1.1 & 17.2 \\
\hline Total & 100.0 & 100.0 & 100.0 & 100.0 \\
\hline
\end{tabular}

*** $p<$.001. Note: The baseline survey was conducted in May 2000, and the postintervention survey, 20 months later.

cational videos, lectures or health consultations, this element was assigned the least weight. The maximum possible treatment score was 12; scores ranged from 0.5 to 9.6, and averaged 4.2 (standard deviation,1.4). Participants with a treatment score lower than 4.2 were categorized as low-treatment, and the remainder were categorized as high-treatment.

The analyses were conducted using the SAS 8.1 statistical software package. The statistical significance of associations between the intervention and outcome variables was evaluated with chi-square tests at a level of .05. For each outcome variable, significance was determined both with and without multivariate statistical adjustments. Using logistic regression, we examined the relative contribution of age, sex, education level, school status, family structure, participants' feeling about their family, family economic status, parental discipline, attitudes toward premarital sex and dating status at baseline to four measures of sexual and contraceptive behavior during the intervention period-sexual initiation, sexual coercion, frequency of contraceptive use and ever-use of condoms.

\section{RESULTS}

\section{Baseline Characteristics}

On average, participants in both the intervention and the control groups were 18.5 years old. The two groups did not differ with respect to age or sex distribution, proportion attending school, family structure, parents' discipline, dating status, attitude toward premarital sex or school type (Table 1). Significant differences were apparent, however, in other baseline characteristics. Higher proportions of youth in the intervention group than of controls had very good feelings toward their family (38\% vs. 30\%) and reported that their family was rich ( $7 \%$ vs. 4\%). Among outof-school youth, those in the intervention group were more highly educated than controls; $61 \%$ and $50 \%$, respectively, had at least a high school education. Similarly, 94\% of intervention participants currently attending school were in high school, compared with 84\% of controls. Among outof-school youth, a smaller proportion of those in the intervention group than of controls were factory workers.

\section{Premarital Sexual Behavior and Contraceptive Use}

At baseline, reported rates of sexual behavior did not differ between the intervention and control groups. In each group, about three in 10 reported having engaged in hugging, two in 10 in kissing and one in 10 in intercourse (Table 2 ). In the postintervention survey, the self-reported rates of these behaviors were considerably higher, but still similar in the two groups: Approximately half of participants reported experience with hugging and kissing, and about one-third said they had had sexual intercourse. In stratified analyses, the reported rates of sexual behavior among out-of-school youth were much higher than those among in-school youth. For example, in the baseline survey, 1\% of students in both the intervention and the control group reported having engaged in sexual intercourse, compared with $16-18 \%$ of out-of-school youth; after the intervention, 8-9\% of students and $48-50 \%$ of out-of-school youth had engaged in sexual intercourse.

Because the intervention emphasized premarital abstinence, we examined the onset of sexual activity among those who had not yet engaged in sexual behavior at baseline (not shown). Of participants who had had no coital experience, $24 \%$ in the intervention group and 25\% in the control group had their first intercourse during the intervention period. There were no significant differences between the groups in the proportions who had their first experiences of hugging, kissing and sexual intercourse.

Among participants who reported coital experience at baseline, frequency of contraceptive use did not differ between the intervention and control groups (Table 2). Onethird of those in the intervention group used a contraceptive method all or most of the time, compared with four in 10 controls. In the postintervention survey, $89 \%$ of sexually active participants in the intervention group reported

\begin{tabular}{|c|c|c|}
\hline Method & $\begin{array}{l}\text { Intervention } \\
(\mathrm{N}=354)\end{array}$ & $\begin{array}{l}\text { Control } \\
(\mathrm{N}=296)\end{array}$ \\
\hline Condom & 96.3 & $67.2^{* * *}$ \\
\hline Withdrawal/periodic abstinence & 41.8 & 43.2 \\
\hline Pill & 20.6 & 25.7 \\
\hline Emergency contraception & 16.7 & $7.1^{* * *}$ \\
\hline Spermicide & 5.9 & $2.4^{*}$ \\
\hline
\end{tabular}


TABLE 4. Percentage of sexually experienced participants reporting selected behaviors during the intervention period, by group assignment

\begin{tabular}{lcc} 
Behavior & Intervention & Control \\
\hline Forced partner into sex & $\mathbf{2 . 8}$ & $\mathbf{8 . 5}$ \\
Males & 4.3 & $11.6^{* *}$ \\
Females & 0.7 & 4.0 \\
Was forced into sex & $\mathbf{2 . 8}$ & $\mathbf{6 . 1 *}$ \\
Males & 2.4 & 4.1 \\
Females & 3.5 & 8.9 \\
Engaged in sexual negotiation & & \\
before intercourse & $\mathbf{8 1 . 0}$ & $\mathbf{5 5 . 1 * * *}$ \\
Males & 81.8 & 57.6 \\
Females & 79.9 & 51.6 \\
Was involved in a pregnancy & $\mathbf{1 8 . 6}$ & $\mathbf{2 5 . 7 *}$ \\
Males & 15.3 & 22.7 \\
Females & 23.5 & 29.8 \\
\hline *p<.05. ${ }^{* *} \mathrm{p}<.01 .{ }^{* * *} \mathrm{p}<.001$. Note: Percentages are based on 209 males and 145 \\
females.
\end{tabular}

having used contraceptives all or most of the time, compared with $45 \%$ of controls; $1 \%$ and $17 \%$, respectively, said they had never used any contraceptive method.

Condoms were the most popular method of contraception used by study participants during the intervention period (Table 3, page 67). However, use of this method was significantly more common in the intervention group than among controls ( $96 \%$ vs. $67 \%$ of sexually experienced youth). Seventeen percent of participants in the intervention group had used emergency contraceptive pills, more than twice the proportion among controls.

\section{Sexual Coercion and Premarital Pregnancy}

Among those who had sexual intercourse during the intervention period, youth in the intervention and control groups differed significantly in the reported rate of sexual coercion (Table 4). Overall, $3 \%$ of intervention participants and $9 \%$ of controls reported having forced a partner into sex. In analyses stratified by sex, the difference also was statistically significant among males ( $4 \%$ vs. $12 \%$ ). The proportion who said they had been forced into sex by a partner also was significantly higher among controls than among intervention participants ( $6 \%$ vs. $3 \%$ ). The intervention group reported use of sexual negotiation techniques before intercourse in greater proportions than did the control group ( $81 \%$ vs. $55 \%$ ).

Nineteen percent of sexually active intervention participants reported having either conceived or impregnated a partner during the intervention period, a significantly lower proportion than the $26 \%$ among controls. However, for both females and males, the evidence for decreased rates of premarital pregnancy does not hold up in stratified analysis.

\section{Multivariate Findings}

-Sexual initiation. The results of the logistic regression analysis suggest that a number of baseline characteristics were associated with whether youth initiated sexual activity during the intervention period (Table 5). For both males and females, the older the youth, the greater the odds of sexual initiation; the odds also were elevated for out-ofschool youth and for those who were dating at baseline. In addition, the likelihood of sexual initiation was reduced for males with at least a high school education and was elevated for males whose parents did not use strict discipline, males who approved of premarital sex and females from single-parent families. The adjusted odds ratio for the intervention group did not differ from that for controls among either males or females, indicating that the program had no direct effect in delaying the onset of premarital sexual activity (model 1). When the intervention participants were categorized as low-treatment or high-treatment (model 2), the results were essentially unchanged.

- Sexual coercion. Participants in the intervention group

TABLE 5. Odds ratios from logistic regression analysis assessing associations between selected characteristics and sexual initiation during the intervention period, by sex

Characteristic

Male $(\mathrm{N}=1,038)$ Female ( $\mathrm{N}=793$

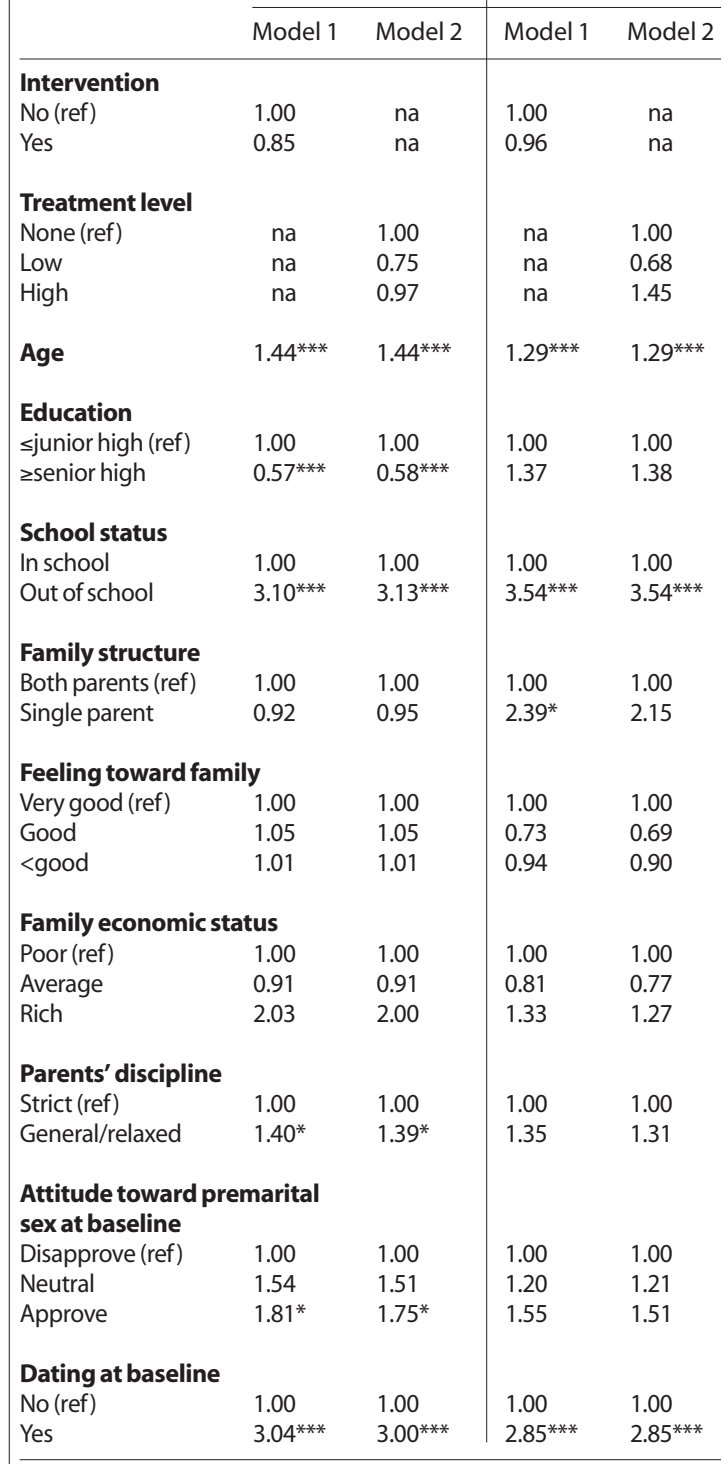

${ }^{*} \mathrm{p}<.05 .{ }^{* * *} \mathrm{p}<.001$. Notes: ref=reference category. na= not applicable. Age is a continuous variable. 
were significantly less likely than controls to have forced their partner into sex during the intervention period: The odds for intervention participants were one-third the odds for controls (Table 6, model 1). Not surprisingly, male youth were more likely to have forced their partner into sex than females. When the intervention group was divided into the two treatment categories (model 2), the results indicate that a high level of treatment was associated with a greater reduction in the odds of sexual coercion than was a low level. - Contraceptive use. Participants in the intervention were more likely than controls to have used contraceptive methods during the intervention period (odds ratio, 6.2). Furthermore, older youth and those reporting a relative high family economic status had increased odds of using contraceptives (Table 6, model 3). When the intervention group was divided by treatment level, the results indicate that greater participation in the intervention was associated with greater use of contraceptives during the intervention period (model 4). - Condom use. The multivariate results assessing ever-use of condoms during the intervention period are consistent with chi-square test results that show greater use in the intervention than in the control group. The odds of intervention participants' reporting ever-use were 13.3 times the odds for controls (Table 6, model 5). Youth whose family economic status was relatively high also had elevated odds of ever using a condom. When the intervention group was divided into two treatment categories, the adjusted odds ratio associated with a high level of treatment was larger than that for a low treatment level, indicating that youth with greater participation in the intervention were more likely to use condoms than those with lower participation (model 6).

\section{DISCUSSION}

In the aggregate, participation in the intervention was not associated with delayed initiation of premarital sexual behavior among the 15-24-year-olds in our sample. This result is consistent with those of sex education programs conducted in the United States. In one comprehensive review, only three out of 11 sex education programs were associated with delayed initiation of intercourse. ${ }^{25}$ Two studies were school-based and focused on postponing sexual intercourse, and the other was an abstinence-only program. Intervention content included self-development, family values, pregnancy, STIs and counseling. The studies were conducted with school-age students, with an age range of 13-18. Perhaps the intervention program in our analysis did not postpone adolescent sexual initiation because it focused on safer sexual practices. In addition, our study sample was older (mean age of 18.5) and therefore more likely to be initiating sexual activity.

Another important finding from this study is that the intervention was associated with a reduced incidence of sexual coercion among participants. We saw a significantly lower occurrence of sexual coercion among intervention participants than among controls. Specifically, males in the intervention group were less likely to report having been TABLE 6. Odds ratios from logistic regression analysis assessing associations between
selected characteristics and sexual coercion, contraceptive use and condom use

\begin{tabular}{|c|c|c|c|c|c|c|}
\hline \multirow[t]{2}{*}{ Characteristic } & \multicolumn{2}{|c|}{ Sexual coercion } & \multicolumn{2}{|c|}{ Contraceptive use } & \multicolumn{2}{|c|}{ Condom use } \\
\hline & Model 1 & Model 2 & Model 3 & Model 4 & Model 5 & Model 6 \\
\hline \multicolumn{7}{|l|}{ Intervention } \\
\hline No (ref) & 1.00 & na & 1.00 & na & 1.00 & na \\
\hline Yes & $0.34^{* *}$ & na & $6.16^{* * *}$ & na & $13.28^{* * *}$ & na \\
\hline \multicolumn{7}{|l|}{ Treatment level } \\
\hline None (ref) & na & 1.00 & na & 1.00 & na & 1.00 \\
\hline Low & na & $0.38^{*}$ & na & $5.27^{* * *}$ & na & $10.12^{* * *}$ \\
\hline High & na & $0.30^{*}$ & na & $7.01^{* * *}$ & na & $15.76^{* * *}$ \\
\hline Age & 0.80 & 0.80 & $1.12^{*}$ & $1.11^{*}$ & 0.95 & 0.95 \\
\hline \multicolumn{7}{|l|}{ Sex } \\
\hline Female (ref) & 1.00 & 1.00 & 1.00 & 1.00 & 1.00 & 1.00 \\
\hline Male & $3.49^{* *}$ & $3.54^{* *}$ & 0.77 & 0.78 & 0.89 & 0.89 \\
\hline \multicolumn{7}{|l|}{ Education } \\
\hline sjunior high (ref) & 1.00 & 1.00 & 1.00 & 1.00 & 1.00 & 1.00 \\
\hline zsenior high & 0.57 & 0.57 & 1.14 & 1.15 & 1.25 & 1.25 \\
\hline \multicolumn{7}{|l|}{ School status } \\
\hline In school & 1.00 & 1.00 & 1.00 & 1.00 & 1.00 & 1.00 \\
\hline Out of school & 1.70 & 1.70 & 1.06 & 1.06 & 1.26 & 1.26 \\
\hline \multicolumn{7}{|l|}{ Family structure } \\
\hline Both parents (ref) & 1.00 & 1.00 & 1.00 & 1.00 & 1.00 & 1.00 \\
\hline Single parent & 0.52 & 0.52 & 0.67 & 0.68 & 1.38 & 1.36 \\
\hline \multicolumn{7}{|c|}{ Feeling toward family } \\
\hline Very good (ref) & 1.00 & 1.00 & 1.00 & 1.00 & 1.00 & 1.00 \\
\hline Good & 1.20 & 1.20 & 0.90 & 0.91 & 0.86 & 0.87 \\
\hline$<$ good & 1.44 & 1.43 & 0.94 & 0.94 & 0.67 & 0.67 \\
\hline \multicolumn{7}{|c|}{ Family economic status } \\
\hline Poor (ref) & 1.00 & 1.00 & 1.00 & 1.00 & 1.00 & 1.00 \\
\hline Average/rich & 0.88 & 0.87 & $1.67^{*}$ & $1.66^{*}$ & $3.66^{* * *}$ & $3.62^{* * *}$ \\
\hline \multicolumn{7}{|c|}{ Parents' discipline } \\
\hline Strict (ref) & 1.00 & 1.00 & 1.00 & 1.00 & 1.00 & 1.00 \\
\hline General/relaxed & 1.39 & 1.40 & 1.25 & 1.24 & 1.39 & 1.37 \\
\hline \multicolumn{7}{|c|}{ Attitude toward premarital sex at baseline } \\
\hline Disapprove (ref) & 1.00 & 1.00 & 1.00 & 1.00 & 1.00 & 1.00 \\
\hline Neutral & 0.75 & 0.74 & 0.92 & 0.94 & 0.89 & 0.91 \\
\hline Approve & 1.06 & 1.06 & 0.89 & 0.91 & 1.13 & 1.17 \\
\hline \multicolumn{7}{|c|}{ Dating at baseline } \\
\hline No (ref) & 1.00 & 1.00 & 1.00 & 1.00 & 1.00 & 1.00 \\
\hline Yes & 0.56 & 0.55 & 0.92 & 0.90 & 1.36 & 1.35 \\
\hline
\end{tabular}

sexually coercive. Additionally, intervention participants, who had been educated in healthy sexual relationships and negotiation skills, were more likely than controls to have used such skills. This intervention was highly successful in promoting consensual behavior and encouraging healthier attitudes toward sex.

Perhaps the most promising findings are that consistent use of contraceptives increased over time among intervention participants and that these youth had higher levels of use of particular methods than their peers in the control group. Adolescents who become sexually active need information about contraceptives and about STI prevention; an exclusive stress on abstinence is no longer applicable to them. Contraceptive knowledge-building and 
distribution programs are more effective for this group than are other sex education programs. ${ }^{26}$ However, this program was controversial, and some parents and two village leaders did not accept it at the beginning of the intervention, on the assumption that educating adolescents about contraceptives and making contraceptives available would increase the likelihood that young people would engage in sexual intercourse and become pregnant. Researchers communicated with these community leaders and parents to help them understand young people's sexual behavior problems and the importance of the intervention. Fortunately, most parents agreed to allow their children to participate. We did not find a significant increase in sexual initiation among those in the intervention group relative to the control group, and the intervention appears to have had a deterrent effect on premarital pregnancy. Hence, contraceptive education and distribution appear to be safe and feasible initiatives even in the conservative Chinese setting.

Our analyses did not assess which of the intervention's components make a difference and whether all components are necessary. However, given the differences between sexually active intervention participants and controls in levels of sexual coercion and contraceptive use, we suggest that negotiation skills, contraceptive education and contraception distribution are important components for sex education programs in China, especially in areas where the proportion of adolescents who are sexually active is high. Small group discussions may also prove effective. Because counseling, contraceptive distribution and life skills training were done primarily through group discussion in this successful intervention, we are inclined to recommend this vehicle for delivering sex education.

Our analysis reveals substantial shifts in participation in sexual activity among youth in both the intervention and the control group over the 20-month intervention period, including a tripling in the proportion reporting having engaged in sexual intercourse. During the 20-month intervention period, many youth in our sample aged into or reached the threshold of a life stage where sexual activity is more normative or acceptable, and we believe that this progression accounts for much of the observed increase in sexual activity. The youngest participant was 17 years old, and $70 \%$ of participants were older than 20 at the conclusion of the intervention period. At this stage in life, making new friends, dating and even establishing serious partnerships are common occurrences. In addition, the increasing openness and acceptance of premarital sexual activity in Chinese society during the intervention period may have contributed to the increase in sexual behavior.

This rapid increase in the prevalence of sexual activity illustrates the urgent need for sex education programs directed at unmarried young people in China. Evidence that the Chinese young adult population is profoundly underinformed with regard to HIV/AIDS, as well as a marked increase in induced abortion among unmarried young women, ${ }^{27}$ suggests that the existing family planning structure is not effectively reaching this vulnerable segment of the population. There is increasing urgency to identify intervention programs that would be most effective in reaching young people and promoting healthy sexual behavior.

\section{Limitations}

Our study has limitations, many of them common to applied research projects. The chosen communities were not randomly assigned to treatment conditions (we chose the intervention township first, then found a comparable township to use as a control), although the matching of the two was an attempt to mitigate the effects of selection bias. The validity of the study's outcomes may also have been threatened by pretest sensitization, because we did not apply the Solomon four-group design, which is useful as a way to control for possible effects of interaction between pretest and intervention. $^{28}$

Another common problem, particularly when behaviors are being measured, involves the use of self-reported, retrospective data. Our evaluation is based on youths' reports of their own behavior. Researchers checked information on sexual behavior and contraceptive use obtained from the baseline survey against data from the postintervention survey for consistency. For example, researchers checked to see if youth who reported sexual intercourse at baseline reported being sexually experienced after the intervention, and if youth who said they used a contraceptive method admitted they had sexual experience. Discrepancies were identified in only $1 \%$ of cases.

Finally, our study is lacking a longer term follow-up questionnaire to determine whether the observed patterns are sustained. We are unable to determine whether the intervention has had any effects on participants' sexual behavior beyond the 20-month period of the study. However, we anticipate that some of the sexual negotiation and contraceptive use patterns will persist at some level.

\section{Conclusion}

The results of this study have implications for other sex education programs. First, this project has shown that largescale, community-based interventions have the potential to make an impact on unmarried youth in areas where a high proportion of youth are engaged in sexual activity. Second, providing comprehensive sex education and reproductive health services to unmarried Chinese youth may help reduce rates of sexual coercion, promote increased contraceptive use and help decrease rates of unwanted pregnancy. Third, life skills training, contraceptive education and contraceptive distribution are important components of comprehensive sex education programs in highly developed regions in China.

\section{REFERENCES}

1. Pan S, A sex revolution in current China, Journal of Psychology and Human Sexuality, 1993, 6(2):1-14

2. Wang T et al., Trends in Chinese sexual behavior, Madison, WI, USA: University of Wisconsin, 2002.

3. Zhang S, An investigation on college students about AIDS knowledge, AIDS Bulletin, 1993, No. 4, pp. 78-81; and Li Z, Investigation on 
adolescent sex-related issues in Guangzhou, Chinese Journal of School Health, 2000, 21(2):105.

4. Tong C, Chen J and Cheng L, A cross-sectional study on causes for induced abortion in Shanghai, Shanghai Medicine, 1999, 22(6):345-348; and Zhang $C$ and Vaughan CE, Student responses to economic reform in China, Adolescence, 1996, 31(123):663-676.

5. Zhang Ket al., Changing sexual attitudes and behavior in China: implications for the spread of HIV and other sexually transmitted diseases, AIDS Care, 1999, 11(5):581-589.

6. Liu X and Liu Y, eds., Almanac of China's Health 2001, Beijing: People's Health Publishing House, 2001.

7. Cao C et al., Reproductive health investigation on 788 unmarried women, Chinese Journal of Maternal and Child Health, 2000, 15(10): 628-629.

8. Zhang L et al., Premarital sexual activities among students in a university in Beijing, China, Sexually Transmitted Diseases, 2002, 29(4): 212-215.

9. Chen X et al., Epidemiologic trends of sexually transmitted diseases in China, Sexually Transmitted Diseases, 2000, 27(3):138-142.

10. Parish W et al., Population-based study of chlamydial infection in China: a hidden epidemic, Journal of the American Medical Association, 2003, 289(10):1265-1273.

11. United Nations Team Group on HIV/AIDS in China, HIV/AIDS: China's Titanic Peril (2002 Update of the AIDS Situation and Needs Assessment Report), Beijing: Joint United Nations Programme on HIV/AIDS, 2002; and Kaufman J and Jing J, China and AIDS-the time to act is now, Science, 2002, 296(5577):2339-2340.

12. Parish W, Yee S and Laumann EO, Going along to get along: female sexual submission in urban China, University of Chicago, <http://www. spc.uchicago.edu/prc/pdfs/parish02.pdf>, accessed July 10, 2004.

13. Cheng Y et al., Sexual coercion among adolescent women seeking abortion in China, Journal of Adolescent Health, 2002, 31(6):482-486.

14. O'Keeffe MK, Nesselhof-Kendall S and Baum A, Behavior and prevention of AIDS: base of research and intervention, Personality and Social Psychology Bulletin, 1990, 16(1):166-180; and Kvalem IL et al., The effect of sex education on adolescents' use of condoms: applying the Solomon four-group design, Health Education Quarterly, 1996, 23(1):34-47.

15. Grunseit A et al., Sexuality education and young people's sexual behavior: a review of studies, Journal of Adolescent Research, 1997, 12(4): 421-453.

16. Franklin C et al., Effectiveness of prevention programs for adolescent pregnancy: a meta-analysis, Journal of Marriage and the Family, 1997, 59(3):551-567; and DiCenso A et al., Interventions to reduce unintended pregnancies among adolescents: systematic review of randomized controlled trials, Primary Care, 2002, 324(7351):1426-1434.

17. Franklin C et al., 1997, op. cit. (see reference 16).

18. Frost JJ and Forrest JD, Understanding the impact of effective teenage pregnancy prevention programs, Family Planning Perspectives, 1995, 27(5):188-195.

19. Jorgensen SR, Potts V and Camp B, Project Taking Charge: six-month follow-up of a pregnancy prevention program for early adolescents, Family Relations, 1993, 42(4):401-406.

20. Jacobs CD and Wolf EM, School sexuality education and adolescent risk-taking behavior, Journal of School Health, 1995, 65(3):91-95.

21. Gao M, Sex health education in university, China Population Today, 1997, 14(2):17-18; and Gao Y et al., AIDS and sex education for young people in China, Reproduction, Fertility and Development, 2001, 13(7-8): 729-737.

22. Shi R, Cai Y and Gao Y, The effectiveness of peer education about AIDS/STDs prevention/safer sex among freshman in an arts college, Reproduction and Contraception, 2003(Special Issue):356-360; and Lou C, Ding Y and Gao E, Sex and reproductive health education among high school students, Reproduction and Contraception, 2003 (Special Issue):346-355.

23. Lou C et al., Effects of a community-based sex education and re- productive health service program on contraceptive use of unmarried youth in Shanghai, Journal of Adolescent Health, 2004, 34(5):433-440.

24. Tu X et al., The status of premarital pregnancy and its influencing factors among the tested women in Shanghai, Medicine and Society, 1998, $11(5): 8-11$

25. Grunseit A et al., 1997, op. cit. (see reference 15).

26. Franklin C et al., 1997, op. cit. (see reference 16).

27. Gao Y et al., 2001, op. cit. (see reference 21); and Cao C et al., 2000, op. cit. (see reference 7).

28. Kvalem IL et al., 1996, op. cit. (see reference 14).

\section{RESUMEN}

Contexto: Más y más adolescentes chinos son sexualmente activos antes de contraer matrimonio. Como resultado de ello, ha aumentado marcadamente el número de embarazos no planeados y los casos de infecciones transmitidas sexualmente (ITS) entre el grupo de jóvenes adultos de China.

Métodos: En un pueblo de las afueras de Shanghai, se llevó a cabo un programa integral de educación sexual, en el cual se incluyó información sobre la abstinencia sexual, la anticoncepción, y la conducta sexual saludable y segura. El programa utilizó seis métodos para suministrar información y servicios a jóvenes de 15-24 años durante un período de 20 meses. Se realizaron encuestas sobre las conductas sexuales entre los participantes y también entre los controles en un pueblo semejante que no habían recibido un servicio comparable; luego se utilizaron pruebas estadísticas de regresión logística y de chi cuadrado para comparar los resultados obtenidos.

Resultados: La participación en esta intervención no estuvo relacionada con la postergación de la iniciación sexual; no obstante, la participación estuvo asociada con menores probabilidades de sexo forzado (razón de momios de 0,3) y con mayores probabilidades del uso anticonceptivo en general $(6,2)$ y del uso del condón en particular $(13,3)$ durante el período de duración del programa. Cuanto mayor fue el nivel de participación, mayores fueron los efectos de protección. Además, el porcentaje de jóvenes que indicaron que tuvieron o causaron casos de embarazo durante esta intervención fue significativamente menor entre los participantes que entre los controles (19\% contra 26\%).

Conclusión: Los programas integrales de educación sexual con base en la comunidad pueden ser eficaces para llegar a un gran número de jóvenes chinos y para promover la negociación sexual (procesos de acuerdo y toma de decisiones en una pareja sexual), el uso de anticonceptivos, y la prevención de las ITS, el VIH y los embarazos.

\section{RÉSUMÉ}

Contexte: De plus en plus d'adolescents chinois s'engagent dans une activité sexuelle prénuptiale. Les nombres de grossesses non planifiées et d'infections sexuellement transmissibles (IST) parmi les jeunes adultes chinois en sont nettement accrus.

Méthodes: Un programme d'éducation complète à la sexualité, couvrant l'abstinence, la contraception et les comportements sexuels sains, a été organisé dans une banlieue de Shanghai. Le programme a mis en ouvre six méthodes d'apport d'information et services aux jeunes célibataires de 15 à 24 ans pendant 
une période de 20 mois. Des enquêtes de comportement sexuel ont été menées parmi les participants à l'intervention et dans un groupe témoin n'ayant pas bénéficié, dans une ville similaire, d'une intervention comparable. Les résultats ont été comparés par tests chi carré et régression logistique.

Résultats: Non associée à une initiation sexuelle différée, la participation à l'intervention s'est révélée liée à une moindre probabilité pour les jeunes de contraindre un/ e partenaire à avoir des rapports sexuels (rapport de probabilités, 0,3) et à une probabilité accrue de pratique contraceptive $(6,2)$ et d'usage du préservatif $(13,3)$ durant la période d'intervention. Plus le niveau de participation était élevé, plus les effets protecteurs l'étaient aussi. La proportion de jeunes déclarant une grossesse durant la période d'intervention s'est également avérée significativement moindre dans le groupe d'intervention que dans le groupe témoin (19\% par rapport à 26\%).

Conclusion: Les interventions communautaires complètes peuvent atteindre de grands nombres de jeunes Chinois et promouvoir efficacement la négociation sexuelle, la pratique contraceptive et la prévention des grossesses et des IST/VIH.

\section{Acknowledgments}

The research on which this article is based was supported by grants from the World Health Organization (WHO) Department of Reproductive Health and Research (project 98289 BSDA). The authors thank WHO, Geneva, and the Department of Reproductive Health and Research for coordinating the study and giving permission to publish this paper, and Elizabeth Thomson and M. Giovanna Merli for helpful comments on an earlier version of it. The study would not have been possible without the dedicated work of many health workers at the Songjiang Family Planning Commission in Shanghai. An earlier version of this paper was presented as a poster at the annual meeting of the Population Association of America, Boston, MA, USA, Apr. 1-3, 2004.

Author contact:wangbo@ssc.wisc.edu 